\title{
Article \\ Temporal Rhythm Affects the Efficiency of Asian Citrus Psyllid (Diaphorina citri) to Acquire Huanglongbing Pathogen
}

\author{
Yan-Jun Guo ${ }^{1,+}$, Yi-Han Li ${ }^{2,3,4,+}$, Zheng-Qin Su ${ }^{2,3}$, Pei-Ping Xu ${ }^{2,3}$, Bao-Li Qiu ${ }^{2,3,4}$ (D), Qian-Hua Ji ${ }^{1}$ \\ and Muhammad Musa Khan 2,3,*
}

check for updates

Citation: Guo, Y.-J.; Li, Y.-H.; Su, Z.-Q.; Xu, P.-P.; Qiu, B.-L.; Ji, Q.-H.; Khan, M.M. Temporal Rhythm Affects the Efficiency of Asian Citrus Psyllid (Diaphorina citri) to Acquire Huanglongbing Pathogen. Agronomy 2021, 11, 1956. https://doi.org/ 10.3390/agronomy11101956

Academic Editors: Pankaj Bhatt and Pilar Soengas

Received: 19 August 2021

Accepted: 27 September 2021

Published: 29 September 2021

Publisher's Note: MDPI stays neutral with regard to jurisdictional claims in published maps and institutional affiliations.

Copyright: (c) 2021 by the authors. Licensee MDPI, Basel, Switzerland. This article is an open access article distributed under the terms and conditions of the Creative Commons Attribution (CC BY) license (https:/ / creativecommons.org/licenses/by/ $4.0 /)$.
1 Institute of Fruit Science, University of Zhaoqing, Zhaoqing 526061, China; yjguo@163.com (Y.-J.G.); qhgee@zqu.edu.cn (Q.-H.J.)

2 Guangdong Laboratory for Lingnan Modern Agriculture, Guangzhou 510642, China; eyvonneli@hotmail.com (Y.-H.L.); zhengqinsu34@foxmail.com (Z.-Q.S.); CURLY_XU@163.com (P.-P.X.); baileyqiu@scau.edu.cn (B.-L.Q.)

3 Key Laboratory of Bio-Pesticide Innovation and Application of Guangdong Province, South China Agricultural University, Guangzhou 510642, China

4 Engineering Research Center of Biocontrol, Ministry of Education of Guangdong Province, Guangzhou 510642, China

* Correspondence: drmusa@scau.edu.cn

+ Both authors contribute equally to this study.

\begin{abstract}
Huanglongbing, commonly known as citrus greening, is a devastating disease of citrus worldwide. Candidatus liberibacter asiaticus is the putative cause of citrus greening disease in China and is spread through the process of plant grafting and feeding by insect vectors. Asian citrus psyllid (Diaphorina citri) is a destructive pest due to insecticide resistance development and the main cause of dissemination of Huanglongbing. The purpose of this study was to determine the level of Huanglongbing present in Guangdong province and the acquisition of the pathogen by $D$. citri through feeding. Six different city areas of Guangdong province were sampled. The results demonstrated that Yunfu currently has the highest infestation rate of CLas in Guangdong province, followed by Chaozhou, Jiangmen, and Foshan. In comparison, Zhongshan and Maoming have the lowest infestation rates. Results also showed that CLas acquisition was directly proportional to the insect feeding duration. The longer an insect fed on an infested plant, the more CLas it acquired. The acquisition efficiency of the pathogen was higher at night compared to during the daytime. During the time period of 15:00-07:00 D. citri acquires more pathogens than during the period of 07:00-15:00. This study provides a basic understanding of the feeding pattern of $D$. citri, which aids in devising a management program for effective control of direct and indirect losses caused by D. citri.
\end{abstract}

Keywords: citrus greening; Candidatus liberibacter; Nested-PCR; feeding duration; infection level; insect vector

\section{Introduction}

Huanglongbing (HLB), or more commonly known as citrus greening, is currently the most devastating citrus disease across citrus-growing regions worldwide [1-3]. The HLB bacteria infects all major citrus varieties, causing a significant financial loss through fruit drop, by making the fruit inedible or unsalable, and by decreasing the lifespan of infected trees [4-6]. Depending on the amount of canopy impacted and the age of the trees at the time of inoculation, yield reductions can range from 30-100\% [2]. Candidatus Liberibacter asiaticus (in Asia and America), Candidatus Liberibacter africanus (in Africa), and Candidatus Liberibacter americanus (in America) are three closely related phloemrestricted $\alpha$-proteobacteria that have been linked to this disease in different regions of the world [6,7]. Citrus Huanglongbing was first recorded in Taiwan [8] and then in Guangdong [9] over a century ago. Koch's postulates have yet to be verified since these bacteria are currently unculturable. Tyler et al. [10] used phloem metagenomic DNA to 
show that Candidatus Liberibacter asiaticus (CLas) is the most common phloem bacteria found in plants with severe HLB symptoms in the United States.

Asian citrus psyllid (ACP) Diaphorina citri Kuwayama (Hemiptera: Liviidae) is considered a destructive pest of citrus in different countries. D. citri is the main source of putative transmission of Candidatus Liberibacter spp. in Asia, Brazil, and the United States, whereas in Africa, Mauritius, and the Reunion Islands both psyllids Trioza erytreae and D. citri and pathogens $C$. Liberibacter africanus and $C$. Liberibacter americanus are present $[1,2,11]$. Citrus psyllid has piercing and sucking mouthparts, and the method of transmitting citrus Huanglongbing is similar to that of other piercing-sucking insects. The pathogen can be obtained by feeding the infected plant and then has a certain incubation period within the insect. Following this, the infected insects keep the ability to transmit the pathogen until they die. In this cycle, an insect vector-pathogen-host triangle is formed: the insects get the bacterium from infected plants and then transmit them to healthy plants $[12,13]$. The spread of Huanglongbing is closely related to the digestive system of the psyllids (midgut and salivary glands). The ability of the digestive system to acquire bacteria is also affected by the feeding habits of the psyllids [14]. Due to the existence of the biological clock, the feeding habits of herbivorous insects have the characteristics of a circadian rhythm [15]. The effect of the feeding habits of citrus psyllids on their bacterial harvesting efficiency is not yet clear. Clarifying its feeding habits can provide a reference for inhibiting the poisoning of psyllids, finding the best application time, and improving the efficiency of Huanglongbing control.

Some of the CLas bacteria transmission properties and parameters by D. citri have been researched previously, but there are still knowledge gaps [16-20]. For example, within 5-7 h of feeding on infected plants, D. citri can obtain the pathogen [1]. However, after 35 days of feeding on infected oranges, just $40 \%$ of adults tested positive for the pathogen using PCR assays [21]. An infected adult female or her mate infects the shoot where she lays her eggs, according to previous studies, then the transferred infection infects whole colony as it develops. Several females may lay their eggs on the same shoot at the same time. That colony can produce hundreds of positive psyllids in a couple of weeks, each of which can repeat the process once they reach maturity. The nymphal stage is the most efficient for acquisition, and an infected nymph can transmit quickly after it emerges as an adult. The disease cycle lasts around three weeks and occurs throughout the life of an infected colony; therefore, even when there are no symptoms, the infective colonization process continues. By the time symptoms appear, the entire grove may be in jeopardy [21-23]. D. citri adults may require a dormant period of 1-25 days after acquiring the pathogen from infected citrus. D. citri adults who have developed on a CLas-infected citrus tree since their nymphal stage have a higher ability to transmit CLas than those who fed on the CLas-infected citrus tree in their adult stage [21,24]. After receiving the pathogen as nymphs, D. citri adults can remain infected with CLas for the remainder of their lives [24]. However, only a small percentage of CLas-exposed D. citri individuals have been observed to be able to inoculate CLas into healthy citrus seedlings (1.3-12.2\%), although significantly larger percentages of these psyllids (up to $90 \%$ ) may test CLas-positive in PCR testing $[17,20]$. Thus, it can be hypothesized that CLas transmission could be hindered in the midgut and salivary glands of D. citri.

The aim of this study was firstly to investigate the current level of CLas infestation across areas of Guangdong province, and secondly, to determine the time required by $D$. citri adults to acquire the CLas from infected plants over different time periods during the day. The information gained aids in devising light management programs for effective control of D. citri.

\section{Materials and Methods}

\subsection{Sample Collection for Citrus Psyllid in Guangdong Province}

Wild-type D. citri adults from M. paniculata were collected from the cities of Jiangmen, Zhongshan, Yunfu, Chaozhou, Foshan, and Maoming of Guangdong province in 2016. 
These areas were chosen due to their high production of citrus. These were Jiangmen, Zhongshan, Yunfu, Chaozhou, Foshan, and Maoming (Figure 1). The collected insects were immersed separately into $95 \%$ ethyl alcohol and frozen at $-20{ }^{\circ} \mathrm{C}$ before being assessed for the presence of Huanglongbing.

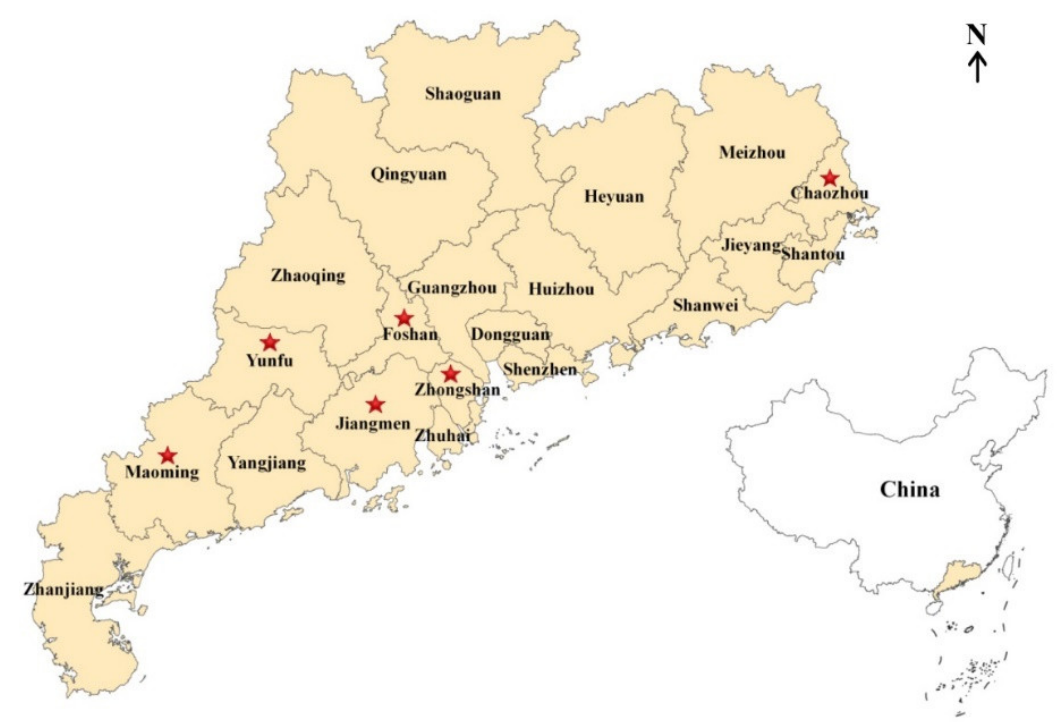

Figure 1. Collection of Asian citrus psyllid within Guangdong province. The map is taken from Li et al. [25] with minor modifications. Red stars represent the city sampling areas.

\subsection{Plants and Insects}

CLas-infected and healthy plants of Citrus reticulata Blanco cv. Shatangju were used in the study. Infected and non-infected plants were collected from the Citrus Research Institute of Zhaoqing University (Guangdong, China), and the CLas-infected plants were inoculated by shoot grafting. All plants were approximately 4 years old and $1.2-1.5 \mathrm{~m}$ in height, separated in nylon net greenhouses (70 mesh per square inch) at two locations approximately $2.2 \mathrm{~km}$ apart within South China Agricultural University (SCAU). Again, Nested-PCR detection was performed periodically (at least once a month) to test for the presence or absence of CLas in the citrus plants according to the method described by Coy et al. [26]. The citrus psyllid was reared on healthy M. paniculata plants in the insect rearing rooms of the Biological Control Engineering Center, Ministry of Education, SCAU. D. citri adults were collected when they were 3 days old for use in the experiments.

\subsection{The Acquisition Time of CLas by D. citri}

\subsubsection{Effect of the Feeding Period}

All the feeding experiments were conducted outdoor under semi-field conditions. Six branches of one CLas-infected citrus plant confirmed to be CLas-positive by PCR before starting were randomly selected. Before treatment, $D$. citri adults were starved for $2 \mathrm{~h}$. At 09:00 in the morning, ten CLas-free $D$. citri adults were released onto a single branch covered with a transparent nylon bag. The adults were removed from the individual branches after $1 \mathrm{~h}, 3 \mathrm{~h}, 5 \mathrm{~h}, 7 \mathrm{~h}, 9 \mathrm{~h}$, and $11 \mathrm{~h}$ of feeding, respectively. Three replications were established for each treatment, meaning 180 (D. citri adults) individuals were investigated in the experiment. The infection of CLas in each adult individual was then measured via PCR.

\subsubsection{Effect of Feeding Time}

To assess the effect of temporal rhythm on the acquisition efficiency of CLas by D. citri, the $24 \mathrm{~h}$ day was divided into three different periods: 07:00-15:00, 15:00-23:00, 23:00-07:00. Before treatment, $D$. citri adults were starved for $2 \mathrm{~h}$. The introduction of $D$. citri was the 
same as with the above description; three branches of one CLas-infected citrus plant were randomly selected and covered by nylon bags. Ten CLas-free $D$. citri adults were released onto each branch at one of the three feeding time periods. Following $8 \mathrm{~h}$ of feeding time, the adults were recaptured and underwent CLas detection via PCR. Three replications were established for each treatment, meaning 90 individuals were investigated. The temperature during the experiments was $25-34{ }^{\circ} \mathrm{C}$ and the relative humidity was $50-90 \%$.

\subsection{Statistical Analysis}

The percentage infestation was determined by using the following formula:

$$
\text { Percentage infestation }(\%)=\frac{\text { Number of ACP infected by CLas }}{\text { Total number of ACP tested }} \times 100
$$

The acquisition of CLas in different experiments was analyzed using One-way ANOVA and the Tukey's post-hoc test to compare the means at $p=0.05$ via SPSS. Sigmaplot 12.0 was used to form graphical work for all the parameters.

\section{Results}

\subsection{Occurrence of CLas-Infected ACP in Guangdong Province}

The percentage of ACP adults infected by CLas in six different areas from Guangdong province varied. The results showed percentage infection rates of $93.33 \%$ in Yunfu, $86.67 \%$ in Chaozhou, 83.33\% in Jiangmen, $80.00 \%$ in Foshan, $66.67 \%$ in Zhongshan, and 63.33\% in Maoming (Figure 2). There was no significant difference in the infection rates of CLas in Chaozhou, Yunfu, Jiangmen, and Foshan, but there was a significant difference among Yunfu, Zhongshan, and Maoming $\left(\mathrm{F}_{4,17}=3.87, p<0.05\right.$; Figure 2).

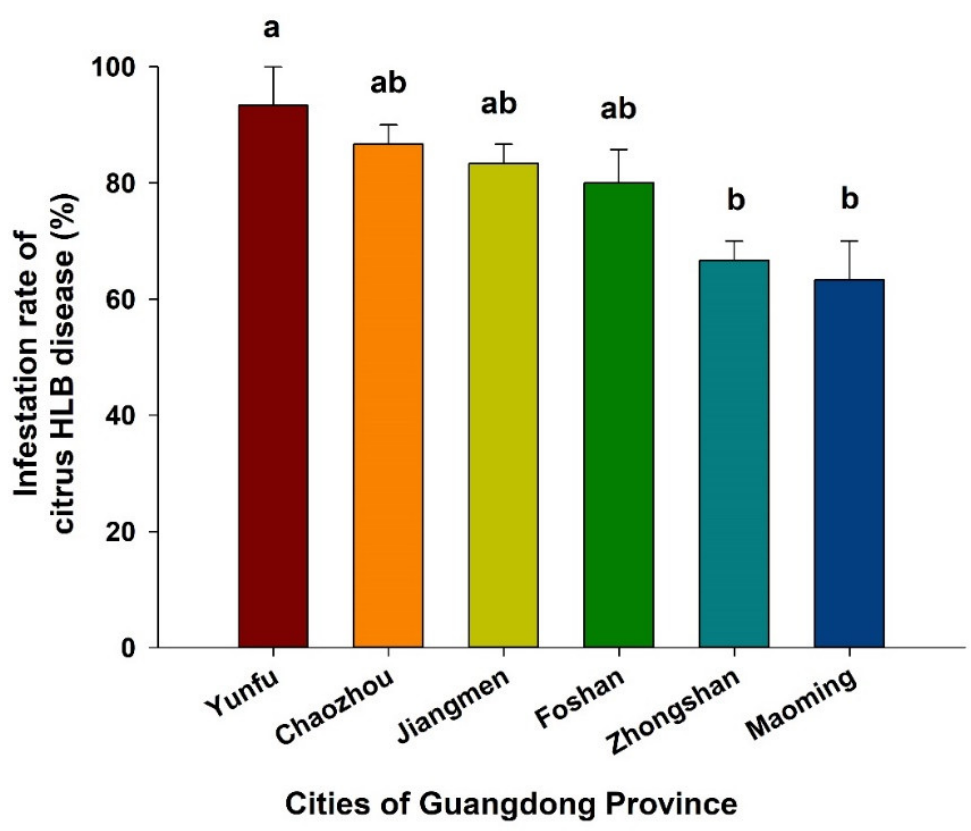

Figure 2. Percentage of $D$. citri adults infected with CLas in different areas of Guangdong province. The bars display the average infection rate from three replications. The standard deviation of the mean is shown by the standard error bars. The significance of the treatments at $p<0.05$ is shown in lowercase lettering. Similar letters represent no significant difference.

\subsection{The Acquisition Time of CLas by D. citri}

\subsubsection{Effect of Feeding Duration}

The acquisition efficiency of CLas by D. citri from CLas-infected citrus plants varied with feeding duration. However, there was no distinct difference among the D. citri adults 
CLas acquisition when adults were fed for $1,3,5$, and $7 \mathrm{~h}$. The CLas titers in D. citri adults fed for 9 or $11 \mathrm{~h}$ were significantly higher than those that fed between $1-7 \mathrm{~h}\left(\mathrm{~F}_{5,17}=10.4\right.$; $p<0.01$; Figure 3).

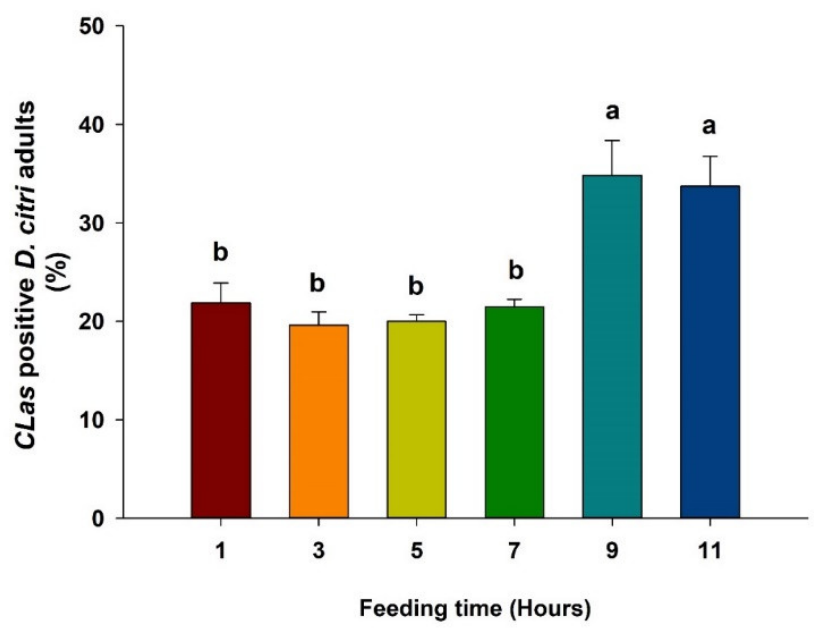

Figure 3. Percentage of CLas-positive D. citri adults feeding on CLas-infected citrus plants for different time durations. The bars display the average from three replications. The standard deviation of the mean is shown by the standard error bars. The significance of the treatments at $p<0.05$ is shown in lowercase lettering. Similar letters represent no significant difference among the treatments.

\subsubsection{Acquisition of CLas in Different Time Durations}

The results showed a significant difference between feeding during the night compared with during the morning period (Figure 4). From high to low, the order was 23:00-07:00: 83.70\% > 15:00-23:00: 73.70\% > 07:00-15:00: 63.33\%. There was no significant difference between the morning and the afternoon period or between the afternoon and the evening period. This indicates that the feeding time was related to the bacteria collection rate, with the results showing that the different feeding times affected the bacterial capture rate of D. citri $\left(\mathrm{F}_{2,8}=6.83 ; p<0.05\right)$.

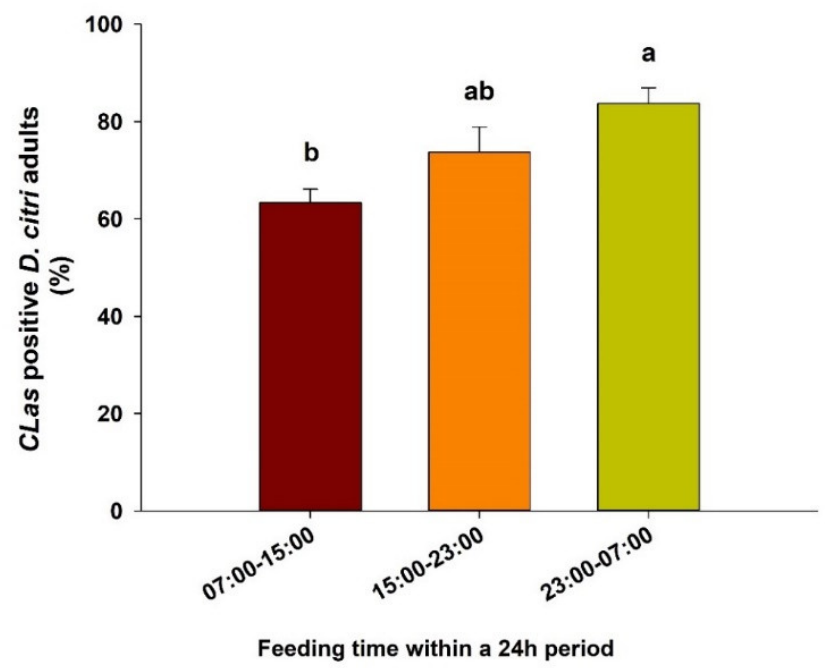

Figure 4. Percentage of CLas-positive D. citri adults feeding on CLas-infected citrus during different periods of the day. The bars display the average over three replications. The standard deviation of the mean is shown by standard error bars. The significance of the treatments at $p<0.05$ is shown in lowercase lettering. Similar letters represent no significant difference among the treatments. 


\section{Discussion}

Huanglongbing has been the most devastating citrus disease worldwide for several decades [2,27]. It impairs phloem transportation of photo-assimilates [27] and causes root decline [28]. Bacterium CLas living in the phloem of a plant prevents direct interactions with other microbes present in the root zone. The CLas causes decreased photo-assimilate transportation, likely reducing plant resource availability for the root-associated microbiome [29].

In recent years, the citrus industry has developed quickly in the Guangxi, Hunan, Jiangxi, Sichuan, Chongqing, and Hubei provinces of China. The changes of citrus production have been calculated for three major regions of production; Zhejiang-FujianGuangdong provinces have been shown to have declined mainly due to increased labor/land costs and from the impact of HLB [30]. Deng et al. [31] reported that geographically, HLB was present in all 12 tested city areas of Guangdong. The current study selected six different cities across Guangdong province to assess the current status of CLas-positive ACP. The results showed that Yunfu is under a high threat of HLB, followed by Chaozhou, Jiangmen, Foshan, Zhongshan, and Maoming.

Although the psyllids we collected were all from Murraya paniculata plants, the survey results showed that the infection rate of CLas in the six regions of Guangdong Province is very high. M. paniculata plants are the recessive host of Huanglongbing. Although CLas pathogens cannot be detected, once the psyllid nymphs have acquired the bacteria and after the CLas bacteria multiplies in the body, the adult can detect many CLas bacteria [17]. There may be many bacteria-carrying citrus seedlings near the planting areas of Citrus reticulata Blanco cv. Shatangju, and the transmission mechanisms of CLas bacteria are very cunning. The mating of male and female adults will also help its transmission [32]. Psyllids multiply through generations, increasing the threat of transmission. These are possible reasons for the positive pathogen of Huanglong in several areas. These results indicate that the citrus psyllid is very harmful to the citrus industry [23].

Asian citrus psyllid D. citri has been considered the main insect vector in the transmission of the CLas pathogen. Previous research has found that $D$. citri is more drawn to CLasinfected plants prior to feeding on them, but that after feeding on infected trees, they are more drawn to uninfected trees, perhaps aiding the pathogen's transmission [33]. Within $0.5-5 \mathrm{~h}$, an uninfected adult ACP fed on a diseased tree can acquire the bacterium [34]. However, a PCR test revealed that only $40 \%$ of ACP adults fed on infected citrus leaves after 35 days were found positive for the pathogen [21].

We found that bacterial acquisition is high at night. The reason for this may be: (1) This experiment was a semi-field experiment, and the temperature could not be controlled. The temperature at night decreased and the feeding behavior of psyllids increased. A study has shown that $25-28{ }^{\circ} \mathrm{C}$ is the optimum temperature for citrus psyllids [35]. At this temperature, the psyllids have the best developmental period and higher survivability. (2) Their feeding is interrupted by predators, farm machinery, etc., during the day. (3) The feeding behavior of psyllids has the characteristics of a circadian rhythm, and an appropriate amount at night is more significant than that during the day.

Circadian clocks synchronize rhythms using a central timekeeper, which controls numerous aspects of physiology and behavior, including feeding and locomotion, the sleep/wake cycle, hormone and neurotransmitter secretion, and developmental events such as molting and metamorphosis [15]. The feeding and digestion of S. littoralis and larval activity and feeding of Heliothis virescens have already been reported to be linked with circadian rhythms [36,37].

For the latent period of pathogens, the time may vary among species. Moll and van Vuuren [38] showed that CLas africanus was acquired by the adult of Trioza erytrae within five days of feeding and entered the salivary gland of the adult between the 21st and 30th day after acquisition feeding, indicating that the latent period is more than 21 days. Capoor et al. [16] showed that the latent period of citrus dieback agents in adult D. citri was 8-12 days. Our present results indicate that the latent period for CLas is variable and 
may be as short as 1-2 days or as long as 23-25 days, depending on the individual D. citri carrier. Xu et al. [34] also reported that a single D. citri adult could acquire CLas to its maximum capacity after 1-2 days of feeding and that this pathogen could remain in the body of $D$. citri throughout its entire life.

Circadian clocks are able to synchronize (entrain) to a new light: dark regime. Insects have adapted their growth and development to use diurnal cycling to modify their activities and increase their fitness [39]. We found that feeding at night from 23:00 to 07:00 $\mathrm{h}$ is the most suitable time for CLas acquisition. However, this could be affected by temperature and other environmental conditions which require further investigation. Changes in the lighting environment will affect the visual ecology and biological clock of pests. Therefore, we can manage pests by manipulating the light environment. New lighting technology provides the possibility to improve the integrated pest management (IPM) of arthropods. Chiel et al. and Doukas and Payne [40-43] found that by regulating the light environment, the colonization efficiency of Bemisia tabaci decreased and the parasitic efficiency of its natural enemy E. formosa increased. El-Aal et al. [44] reported that the vitality of cotton aphids can be controlled by adjusting light conditions.

\section{Conclusions}

The CLas infection in ACP is very high in the Yunfu and Chaozhou city areas of Guangdong province. The efficiency of CLas acquisition by D. citri is affected by its feeding duration and feeding time on infected plants. The bacterial acquisition is higher at night compared to the daytime. This study gives a basic understanding of the feeding pattern of $D$. citri, which could aid in developing better control by incorporating light management techniques in integrated pest management (IPM).

Author Contributions: Conceived and designed the experiments: Y.-J.G., Q.-H.J. and B.-L.Q. Performed the experiments: Y.-J.G., Y.-H.L., Z.-Q.S., P.-P.X. and M.M.K. Analyzed the data: Y.-J.G. and Y.-H.L. Contributed reagents/materials/analysis tools: Q.-H.J. Wrote the paper: Y.-J.G., M.M.K., Y.-H.L. and B.-L.Q. All authors have read and agreed to the published version of the manuscript.

Funding: This work was supported by the Laboratory of Lingnan Modern Agriculture Project (NT2021003), NSFC-Guangdong Joint Research Fund (U1701231), China Agriculture Research System of MOF and MARA Fund, the National High Level Talent Special Support Plan (2020) and the Earmarked Fund for Guangdong Modern Agro-Industry Technology Research System (2021KJ108).

Data Availability Statement: Not applicable.

Acknowledgments: We thank Andrew G. S. Cuthbertson (York, UK) for his critical comments on an earlier version of the manuscript.

Conflicts of Interest: All authors have read and approved the manuscript for publication. The authors declare no competing interests.

\section{References}

1. Halbert, S.; Manjunath, K. Asian citrus psyllids (Sternorrhyncha: Psyllidae) and greening disease of citrus: A literature review and assessment of risk in Florida. Florida Entomol. 2004, 87, 330-353. [CrossRef]

2. Gottwald, T.R. Current epidemiological understanding of citrus huanglongbing. Annu. Rev. Phytopathol. 2010, 48, 119-139. [CrossRef] [PubMed]

3. Hall, D.G.; Richardson, M.L.; Ammar, E.D.; Halbert, S.E. Asian citrus psyllid, Diaphorina citri, vector of citrus huanglongbing disease. Entomol. Exp. Appl. 2013, 146, 207-223. [CrossRef]

4. Miyakawa, T. Experimentally induced symptoms and host range of citrus likubin (greening disease). Ann. Phytopathol. Soc. Jpn. 1980, 46, 224-230. [CrossRef]

5. da Graca, J.V. Citrus greening disease. Annu. Rev. Phytopathol. 1991, 29, 109-136. [CrossRef]

6. Bové, J.M. Huanglongbing: A destructive, newly-emerging, century-old disease of citrus [Asia; South Africa; Brazil; Florida]. J. Plant Pathol. 2006, 88, 7-37.

7. Garnier, M.; Jagoueix-Eveillard, S.; Cronje, P.R.; Le Roux, H.F.; Bové, J.M. Genomic characterization of a liberibacter present in an ornamental rutaceous tree, Calodendrum capense, in the Western Cape province of South Africa. Proposal of "Candidatus liberibacter africanus subsp. capensis". Int. J. Syst. Evol. Microbiol. 2000, 50, 2119-2125. [CrossRef]

8. Sawada, K. Citrus Likubing(pre-report). Taiwan Agric. Rep. 1913, 83, 903-914. 
9. Reinking, O.A. Diseases of economic plants in southern China. Philipp. Agric. 1919, 8, 109-134.

10. Tyler, H.L.; Roesch, L.F.W.; Gowda, S.; Dawson, W.O.; Triplett, E.W. Confirmation of the sequence of "Candidatus liberibacter asiaticus" and assessment of microbial diversity in huanglongbing-infected citrus phloem using a metagenomic approach. Mol. Plant-Microbe Interact. 2009, 22, 1624-1634. [CrossRef]

11. Aubert, B. Trioza erytreae del Guercio and Diaphorina citri Kuwayama (Homoptera: Psylloidea), the two vectors of citrus greening disease: Biological aspects and possible control strategies. Fruits 1987, 42, 149-162.

12. Li, Y. Molecular Detection of Endosymbiont in Citrus Psyllid and the Relation between Feeding Time and Efficiency of Bacteria in Citrus Psyllid. Master's Thesis, South China Agricultural University, Guangzhou, China, 2016.

13. Hosseinzadeh, S.; Shams-bakhsh, M.; Mann, M.; Fattah-hosseini, S. Distribution and variation of bacterial endosymbiont and "Candidatus Liberibacter asiaticus" titer in the Huanglongbing insect vector, Diaphorina citri Kuwayama. Microb. Ecol. 2019, 78, 206-222. [CrossRef]

14. Cicero, J.M.; Brown, J.K.; Roberts, P.D.; Stansly, P.A. The digestive system of Diaphorina citri and Bactericera cockerelli (Hemiptera: Psyllidae). Ann. Entomol. Soc. Am. 2009, 102, 650-665. [CrossRef]

15. Zhang, J.; Li, S.; Li, W.; Chen, Z.; Guo, H.; Liu, J.; Xu, Y.; Xiao, Y.; Zhang, L.; Arunkumar, K.P.; et al. Circadian regulation of night feeding and daytime detoxification in a formidable Asian pest Spodoptera litura. Commun. Biol. 2021, 4, 286. [CrossRef]

16. Capoor, S.; Rao, G.; Viswanath, S. Greening disease of citrus in the Deccan Trap Country and its relationship with the vector, Diaphorina citri Kuwayama. In Proceedings of the 6th Conference of International Organization of Citrus Virologists, Swaziland, Eswatini, 21-28 August 1972; pp. 43-49.

17. Hung, T.H.; Hung, S.C.; Chen, C.N.; Hsu, M.H.; Su, H.J. Detection by PCR of Candidatus Liberibacter asiaticus, the bacterium causing citrus huanglongbing in vector psyllids: Application to the study of vector-pathogen relationships. Plant Pathol. 2004, 53, 96-102. [CrossRef]

18. Brlansky, R.H.; Rogers, M.E.; Alfred, L. Citrus Huanglongbing: Understanding the Vector-Pathogen Interaction for Disease Management. APSnet 2008, 8, 1-9. [CrossRef]

19. Ammar, E.D.; Shatters, R.G.; Hall, D.G. Localization of Candidatus Liberibacter asiaticus, Associated with Citrus Huanglongbing Disease, in its Psyllid Vector using Fluorescence in situ Hybridization. J. Phytopathol. 2011, 159, 726-734. [CrossRef]

20. Ammar, E.D.; Shatters, R.G.; Lynch, C.; Hall, D.G. Detection and relative titer of Candidatus liberibacter asiaticus in the salivary glands and alimentary canal of Diaphorina citri (Hemiptera: Psyllidae) vector of citrus huanglongbing disease. Ann. Entomol. Soc. Am. 2011, 104, 526-533. [CrossRef]

21. Pelz-Stelinski, K.S.; Brlansky, R.H.; Ebert, T.A.; Rogers, M.E. Transmission parameters for Candidatus Liberibacter asiaticus by Asian citrus psyllid (Hemiptera: Psyllidae). J. Econ. Entomol. 2010, 103, 1531-1541. [CrossRef] [PubMed]

22. Inoue, H.; Ohnishi, J.; Ito, T.; Tomimura, K.; Miyata, S.; Iwanami, T.; Ashihara, W. Enhanced proliferation and efficient transmission of Candidatus Liberibacter asiaticus by adult Diaphorina citri after acquisition feeding in the nymphal stage. Ann. Appl. Biol. 2009, 155, 29-36. [CrossRef]

23. Lee, A.J.; Halbert, S.E.; Dawson, W.O.; Robertson, C.J.; Keesling, J.E.; Singer, B.H. Asymptomatic spread of huanglongbing and implications for disease control. Proc. Natl. Acad. Sci. USA 2015, 112, 7605-7610. [CrossRef]

24. Huang, C.; Tsai, Y.; Wang, C. Transmission of citrus likubin by a psyllid, Diaphorina citri. J. Agric. Res. China 1984, 33, 65-72.

25. Li, C.; Kuang, Y.; Huang, N.; Zhang, C. The long-term relationship between population growth and vegetation cover: An empirical analysis based on the panel data of 21 cities in guangdong province, China. Int. J. Environ. Res. Public Health 2013, 10, 660-677. [CrossRef]

26. Coy, M.R.; Hoffmann, M.; Kingdom Gibbard, H.N.; Kuhns, E.H.; Pelz-Stelinski, K.S.; Stelinski, L.L. Nested-quantitative PCR approach with improved sensitivity for the detection of low titer levels of Candidatus Liberibacter asiaticus in the Asian citrus psyllid, Diaphorina citri Kuwayama. J. Microbiol. Methods 2014, 102, 15-22. [CrossRef]

27. Wang, N.; Trivedi, P. Citrus huanglongbing: A newly relevant disease presents unprecedented challenges. Phytopathology 2013, 103, 652-665. [CrossRef]

28. Johnson, E.G.; Wu, J.; Bright, D.B.; Graham, J.H. Association of "Candidatus Liberibacter asiaticus" root infection, but not phloem plugging with root loss on huanglongbing-affected trees prior to appearance of foliar symptoms. Plant Pathol. 2014, 63, 290-298. [CrossRef]

29. Zhang, Y.; Xu, J.; Riera, N.; Jin, T.; Li, J.; Wang, N. Huanglongbing impairs the rhizosphere-to-rhizoplane enrichment process of the citrus root-associated microbiome. Microbiome 2017, 5, 97. [CrossRef]

30. Zhou, C. The status of citrus Huanglongbing in China. Trop. Plant Pathol. 2020, 45, 279-284. [CrossRef]

31. Deng, X.L.; Gao, Y.D.; Chen, J.C.; Pu, X.L.; Kong, W.W.; Li, H.P. Curent situation of "Candidatus Liberibacter asiaticus" in Guangdong, China, where citrus Huanglongbing was first described. J. Integr. Agric. 2012, 11, 424-429. [CrossRef]

32. Halbert, S.; Singer, B. Epidemiology of Huanglongbing: Imolication of infective colonization events. In Asian Citrus Psyllid: Biology, Ecology and Management of the Huanglongbing Vector; Qureshi, J.A., Stansly, P.A., Eds.; CABI Publishing: Gainesville, FL, USA, 2020; pp. 140-155.

33. Mann, R.S.; Ali, J.G.; Hermann, S.L.; Tiwari, S.; Pelz-Stelinski, K.S.; Alborn, H.T.; Stelinski, L.L. Induced release of a plantdefense volatile "deceptively" attracts insect vectors to plants infected with a bacterial pathogen. PLoS Pathog. 2012, 8, e1002610. [CrossRef] [PubMed] 
34. Xu, C.F.; Xia, Y.H.; Li, K.B.; Ke, C. Further study of the transmission of citrus huanglongbing by a psyllid, Diaphorina citri Kuwayama. In Proceedings of the 10th Conference of the International Organization of Citrus Virologists, Valencia, Spain, 17-21 November 1986; pp. 243-248.

35. Ying, B.; Liu, H.; Tsai, J.H. Effects of temperature on biology and life table parameters of the Asian citrus psyllid, Diaphorina citri Kuwayama (Homoptera: Psyllidae). Annu. Appl. Biol. 2000, 137, 201-206.

36. Suszczynska, A.; Kaniewska, M.M.; Bebas, P.; Giebultowicz, J.M.; Kotwica-Rolinska, J. Circadian regulation of caterpillar feeding and growth. J. Insect Physiol. 2017, 101, 113-122. [CrossRef]

37. Niepoth, N.; Ke, G.; de Roode, J.C.; Groot, A.T. Comparing Behavior and Clock Gene Expression between Caterpillars, Butterflies, and Moths. J. Biol. Rhythm. 2018, 33, 52-64. [CrossRef]

38. Moll, J.N.; Van Vuuren, S.P. Greening disease in Africa. In Proceedings of the International Society of Citriculture, Orlando, FL, USA, 1-8 May 1977; pp. 903-912.

39. Nalam, V.; Isaacs, T.; Moh, S.; Kansman, J.; Finke, D.; Albrecht, T.; Nachappa, P. Diurnal feeding as a potential mechanism of osmoregulation in aphids. Insect Sci. 2021, 28, 521-532. [CrossRef]

40. Chiel, E.; Messika, Y.; Steinberg, S. The effect of UV-absorbing plastic sheet on the attraction and host location ability of three parasitoids: Aphidius colemani, Diglyphus isaea and Eretmocerus mundus. BioControl 2006, 51, 65-78. [CrossRef]

41. Doukas, D.; Payne, C.C. Effects of UV-blocking films on the dispersal behaviour of Encarsia formosa (Hymenoptera: Aphelinidae). J. Econ. Entomol. 2007, 100, 110-116. [CrossRef]

42. Doukas, D.; Payne, C.C. Greenhouse whitefly (Homoptera: Aleyrodidae) dispersal under different UV-light environments. J. Econ. Entomol. 2007, 100, 389-397. [CrossRef] [PubMed]

43. Doukas, D.; Payne, C.C. The use of ultraviolet-blocking films in insect pest management in the UK; effects on naturally occurring arthropod pest and natural enemy populations in a protected cucumber crop. Ann. Appl. Biol. 2007, 151, 221-231. [CrossRef]

44. El-aal, H.A.A.; Rizk, A.M.; Mousa, I.E. Evaluation of new greenhouse covers with modi fi ed light regime to control cotton aphid and cucumber (Cucumis sativus L.) productivity. Crop Prot. 2018, 107, 64-70. [CrossRef] 